\title{
Front Matter: Volume 10263
}

, "Front Matter: Volume 10263," Proc. SPIE 10263, Lens Design: A Critical Review, 1026301 (1 July 1992); doi: 10.1117/12.2284709

SPIE. Event: OE/LASE '92, 1992, Los Angeles, CA, United States 


\section{Contents}

vii Conference Committee

ix Preface

\section{Session 1}

2 First-order layout: from imagery to achromatism to athermalization to cost W. J. Smith, Kaiser Electro-Optics, Inc.

18 Historical perspective on understanding optical aberrations

R. B. Johnson, Ctr. for Applied Optics/Univ. of Alabama in Huntsville

$30 \quad$ Principles of lens design

M. J. Kidger, Kidger Optics Ltd. (UK)

54 Evolution of optimization algorithms

G. K. Hearn, SCIOPT Enterprises

\section{Session 2}

72 Monochromatic quartet explained

D. M. Williamson, SVG Lithography Systems Inc.

88 Zoom lens principles and types

E. I. Betensky, Opcon Associates, Inc.

117 What's so different about IR lens design?

R. E. Fischer, OPTICS 1, Inc.

140 Predesign of diamond-turned refractive/diffractive elements for IR objectives M. J. Riedl, OFC Corp.

\section{Session 3}

158 Application of diffractive optical elements in visible and infrared optical systems

C. W. Chen, Hughes Aircraft Co.

173 Aircraft head-up displays from refractors to holograms

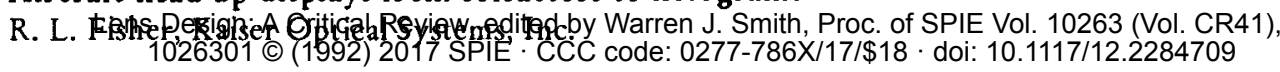


192 Potential pitfalls in the design of $x$-ray/EUV imaging systems J. E. Harvey, CREOL/Univ. of Central Florida

225 Eccentric-pupil reflecting-telescope development E. W. Cross, Jr., Cross Optics

\section{Session 4}

270 Design of apochromats and superachromats

R. I. Mercado, Nikon Precision, Inc.

297 Geometrical or Gaussian: where is that image anyway?

A. S. Y. Lau, Hughes Aircraft Co.

310 The last three-mirror anastigmat?

L. G. Cook, Hughes Aircraft Co.

325 Microscope objectives and their evolution to optical disk objectives

B. G. Broome, Optical Research Associates

349 Optics/vision interface

P. J. Rogers, Pilkington PE Ltd. (UK) 


\title{
Conference Committee
}

\author{
Conference Chair
}

Warren J. Smith, Kaiser Electro-Optics, Inc.

Cochairs

Lacy G. Cook, Hughes Aircraft Company

Robert E. Fischer, OPTICS 1, Inc.

R. Barry Johnson, Center for Applied Optics/University of Alabama in Huntsville

Session Chairs

Session 1

Lacy G. Cook, Hughes Aircraft Company

Session 2

Philip J. Rogers, Pilkington Optronics (UK)

Session 3

R. Barry Johnson, Center for Applied Optics/University of Alabama in Huntsville

Session 4

Donald C. Dilworth, Optical Systems Design, Inc. 


\section{Preface}

This critical review of lens design incorporates the work of no fewer than seventeen acknowledged experts in the field, each of whom has presented an authoritative review of some particular aspect of lens design. Mathematical lens design has existed since 1840, when Joseph Max Petzval designed his renowned Portrait Lens. Lens design and geometrical optics are well-established fields, yet they still grow and advance. Each year there are more and more individuals practicing lens design, and each year the art, the science, the tools, and the techniques of lens design show incremental advances.

In this review we have attempted to provide both a broad coverage of the basic elements of lens design as well as review of particular subjects that have undergone recent advances and innovations. Our first session included the basics of first-order optics, aberrations, design principles, and computer optimization programs. In the second session the ILDC lens design contest winner presented the winning design. Recent developments in zoom lenses and the peculiarities of IR lens design were covered, as well as the design and fabrication of a real diffractive/refractive lens. The third session included more on diffractive lens design, plus holographic applications in HUDs, a discussion of the special considerations of UV and $x$-ray optics, and a narration of the development of an eccentric pupil-reflecting telescope. The final session began with a paper on apochromats and superachromats, and another on the diffraction effects of a gaussian distribution of beam intensity. Up-to-date coverage of mirror anastigmats was followed by a review of microscope-objective development through the current optical disk applications. The session ended with a discussion of the interface between optics and the eye.

All in all it was a pleasant and instructive blend of background and new outlooks on the subject at hand. This volume should become a highly regarded reference and a worthy companion to the now-classic Critical Reviews of Geometrical Objects (1985, SPIE Vol. 531, R. E. Fischer, W. H. Price, and W. J. Smith, eds.). I would like to express $m$ y gratitude and appreciation to the cochairs, the experts who spoke, and the experts who attended and contributed to the discussions.

Warren J. Smith

Kaiser Electro-Optics, Inc. 